\title{
Bilevel Multiobjective Programming Applied to Water Resources Allocation
}

\author{
Shiqi Fang, ${ }^{1}$ Ping Guo, ${ }^{1,2}$ Mo Li, ${ }^{1}$ and Liudong Zhang ${ }^{1,3}$ \\ ${ }^{1}$ Centre for Agricultural Water Research in China, China Agricultural University, Beijing 100083, China \\ ${ }^{2}$ Environmental Science and Engineering Program, University of Northern British Columbia, Prince George, BC, Canada V2N $4 Z 9$ \\ ${ }^{3}$ College of Water Conservancy, Hydropower and Architecture Engineering, Yunnan Agricultural University, Kunming 650201, China
}

Correspondence should be addressed to Ping Guo; guop@cau.edu.cn

Received 28 November 2012; Accepted 3 February 2013

Academic Editor: Yongping Li

Copyright (c) 2013 Shiqi Fang et al. This is an open access article distributed under the Creative Commons Attribution License, which permits unrestricted use, distribution, and reproduction in any medium, provided the original work is properly cited.

Water allocation is an essential programming to support the sustainable development of Wuwei Basin, Gansu Province, China. To satisfy the demands of the decision makers (DMs) of each subarea and the total area, a bilevel multiobjective linear programming (BLMOLP) model is proposed. In the BLMOLP, DMs have a hierarchy of two levels-the upper level and the lower level DMs. In this paper, a fuzzy goal programming (FGP) approach is applied to solve the BLMOLP. Firstly, the upper level is solved and used as the tolerance for the lower level. Then the weights of each objective function in the lower level are evaluated. Finally, a satisfied optimization solution of the problem was calculated. The result suggests that the FGP is a simple and feasible approach to BLMOLP problems. The proposed method was applied to a case study for water resources allocation in Wuwei Basin. For four scenarios under consideration, the model can effectively balance the benefits among all regions and sections according to the priority of the upper level decision makers. The results indicate that comprehensive solutions have been obtained.

\section{Introduction}

Water is essential for all forms of life and is a fundamental resource, which has benefited both people and their socioeconomies for many centuries $[1,2]$. The services provided by water systems are multiple. Yet, the overgrowing population and the droughts are putting water resources under pressure, especially in arid and semiarid areas. Solutions to the problem depend on many factors among which rational water planning and management is essential [3]. Water resources management has been a popular problem since the 1990s. Many researchers have promoted many concepts and methods for sustainable water resources management, such as virtual water and water foot print.

To balance the conflicts among water users, researchers have introduced optimization models for the allocation of water resources. The earlier water resource optimization models have been applied to multiarid and semiarid areas all over the world, from Arizona [4] to southern California [5] from Africa [6, 7] to Asia [8]. There are different methods introduced in the literature for optimization models of water resources allocation, such as dynamic programming [9], genetic algorithm [10], and game theoretic approach [11]. In the progress of decision making, problems are often compounded by uncertainties, such as the rainfall and the runoff appeared random values. In recent years, to tackle these uncertainties, several scientists proposed kinds of novel approaches. Messner et al. [12] proposed a multicriteria decision support under uncertainty, to deal with the water allocation conflict in the watershed of the German Spree River. To handle uncertainties existing in the water resources management systems, Li et al. [13] applied a multistage fuzzystochastic programming (MFSP) model to the planning of sustainable water resources management. In water allocation problem, Sadegh et al. [14] developed new methodologies based on game theories for optimal allocation of interbasin water resources, and Sadegh and Kerachian [15] then developed two new concepts Fuzzy Least Core and Fuzzy Weak Least Core to solve the water allocation model with fuzzy cooperative games. Shao et al. [16] combined conditional valueat-risk (CVaR) model with inexact two-stage stochastic programming and applied it to a reservoir water allocation 
system. Jin et al. [17] applied a dynamic dual interval programming (DDIP) to the irrigation water allocation systems. It is composed of potato, wheat, and alfalfa users with different requirements of water demand, value, and penalty cost under uncertainty. However, these methods have seldom been applied in practical cases for water resources allocation because of their complexity.

In practical cases, research area contains several subareas with multiwater users, such as irrigation, industry, domesticity, and ecology users. Competition for scare water resources by these users demands more well-developed methods to solve the conflicts, thus the researchers turned to multiobjective programming. Xevi and Khan [18] developed a multicriteria decision-making (MCDM) framework under multiconstraints, using the goal programming (GP) to solve the multiple objective problems. Singh et al. [19] presented an interactive fuzzy multiobjective linear programming (IFMOLP) model to improve the water quality and reduce the treatment cost. Fasakhodi et al. [20] were concerned with multiobjective linear fractional programming for optimizing sustainable water resources management. Many of them might encounter with the problem that it is difficult to select the target values and weights for the different goals.

However, water users and water managers always belong to two different groups in water system, especially in China. So there are not only conflicts between water users but also conflicts between water users and managers. And all the users have a hierarchical organization, so we need a multilevel or a bilevel programming to solve such a problem. Multilevel programming and bilevel programming were first proposed by Candler and Norton in their report [21]. Multi-level programming (MLP) is identified as mathematical programming that solves decentralized planning problems with multiple executors in a multi-level or hierarchical organization [22]. A bilevel programming problem is a special MLP that bilcontains decision makers (DMs) in two levels. Bilevel programming has been used in water exchange in eco-industrial parks [23], manufacturer-retailer supply chain problems [24], and lot-sizing problems [25]. Considering a water resources allocation problem that involves multisources and multiusers, Lv et al. [26] developed an interval fuzzy bilevel approach (IFBP) to solve the problems, from which decision makers had a characteristic of hierarchy and conflicted with each other. However, there are few researches to address the bilevel approach within multiobjective framework under uncertainty for the water resources allocation. Especially when managers need to make a choice among multiprofits, traditional mathematical programming cannot deal with such dilemma under a hierarchical structure.

Based on the above discussions, in water allocation behavior, different interest users and different interest managers have different objectives which may be conflicting and incommensurable. When water managers considered water allocation problem referring to targets on different levels, a bilevel programming can be used for different profit preference. Such as in the Wuwei Basin, environment and ecology deterioration is the most prominent problem, so the decision makers on the upper level can place particular emphasis on the ecology benefit. To coordinate their interests, a bilevel approach within multiobjective framework under uncertainty for the water resources allocation needs to be considered. In this research, a bilevel multiobjective linear programming (BLMOLP) is proposed to solve water resources allocation for multiusers, which were characterized as hierarchical structure. The detailed research tasks include the following. In Section 2, the general formulation and the solution methods are introduced. The fuzzy goal programming approach is mainly discussed and used to solve the problem. In Section 3, the general situation of the study area is presented, and the formulation of the problem is solved. Four scenarios are calculated for different goals, and the results will help the decision makers to balance the water allocation in the area. In Section 4, the conclusion is given, and the future work is proposed.

\section{Methodology}

\subsection{Bilevel Programming}

2.1.1. General Formulation. The general formulation of a bilevel programming problem (BLPP) is as follows [27]:

(upper level)

$$
\begin{array}{ll}
\max _{x \in X, y} & F(x, y) \\
\text { s.t. } & G(x, y) \leq 0,
\end{array}
$$

where $y$ can be solved from

(lower level)

$$
\begin{array}{cl}
\max _{y} & f(x, y) \\
\text { s.t. } & g(x, y) \leq 0,
\end{array}
$$

where $x \in \mathbf{R}^{n_{1}}$ and $y \in \mathbf{R}^{n_{2}}$. The variables of problem (1), (2), (3), (4), and (5) are divided into two classes, namely, the upper level variables $x \in \mathbf{R}^{n_{1}}$ and the lower level variables $y \in \mathbf{R}^{n_{2}}$. The upper level decision maker (ULDM) controls over vector $x$, and the lower level decision maker (LLDM) controls over vector $y$.

Through introducing the bilevel programming into the multiobjective framework, the bilevel multiobjective linear programming (BLMOLP) can be expressed as

(upper level)

$$
\begin{array}{cl}
\max _{x \in X, y} & F(x, y) \\
\text { s.t. } & G(x, y) \leq 0,
\end{array}
$$

where $y$ can be solved from

(lower level)

$$
\begin{array}{cl}
\max _{y} & \left\{f_{1}(x, y), \ldots, f_{i}(x, y), \ldots, f_{n}(x, y),\right\} \\
\text { s.t. } & g_{i}(x, y) \leq 0 .
\end{array}
$$

2.1.2. Solution Methods. So far, many classical approaches to solve bilevel programming (BLP), especially for bilevel linear 
programming, were developed. The $K$ th-best algorithm was first proposed by Candler and Townsley [28]. Shi et al. [29] proposed an extended $K$ th-best approach for linear BLP. Bialas and Karwan [30] first used complementary pivots approach for linear BLPPs. Also, Bard and Moore [31] proposed the branch and bound algorithm to solve bilevel programming. This algorithm has been applied with remarkable success in linear bilevel programming, but its performance is dependent on the linear form of the upper level constraint functions.

One of the most efficient approaches was the fuzzy goal programming (FGP), which is an extension of the conventional goal programming (GP) introduced by Charnes and Cooper [32]. Fuzzy goal programming (FGP) approach to BLP has been recently studied by many researchers [33-35].

\subsection{Fuzzy Goal Programming to BLMOLP. In BLMOLP} problems, if one level is assigned to each of the objectives, then these fuzzy objectives are termed as fuzzy goals. They are to be characterized by the associated membership functions by defining the tolerance limits for the achievement of each level. And the solution procedure appears as the following $[22,36,37]$.

2.2.1. Construction of Membership Functions. If the two levels share the same constrains, all the DMs are interested in maximizing their own objective functions over the same feasible region, then the optimal solutions of both of them calculated in isolation can be taken as the aspiration levels of their associated fuzzy goals.

Let $\left(x^{U}, y^{U}, F^{U}\right)$ and $\left(x^{L}, y^{L}, f^{L}\right)$ be the optimal solutions of the upper level and lower level, respectively, when calculated in isolation. Then the fuzzy goals of leader and subordinates appear as

$$
F \gtrsim F^{L}, \quad f_{i} \gtrsim f_{i}^{U}
$$

It may be noticed that the two solutions $\left(x^{U}, y^{U}, F^{U}\right)$ and $\left(x^{L}, y^{L}, f^{L}\right)$ are usually different because the objectives of all DMs are conflicting in nature. Therefore, it can be assumed reasonably that the values $F^{L}\left[=F\left(x^{L}, y^{L}\right)\right]<F^{U}$ and all values $F(x, y)<F^{L}$ are absolutely unacceptable to the upper level. $f\left(x^{m}, y^{m}\right)$ can be considered as the tolerance limit of the fuzzy objective goal of the upper level. Similarly, $f^{U}[=$ $\left.f\left(x^{U}, y^{U}\right)\right]<f^{L}$ can be considered as the lower tolerance limit of the fuzzy objective goal of the lower level.

Let $x^{m}\left(x^{L}<x^{m}<x^{U}\right)$ be the tolerance limit of the fuzzy decision goal of the leader. Then, the membership functions of the defined fuzzy goals can be formulated as follows:

$$
\mu_{F}[F(x, y)]= \begin{cases}1 & \text { if } F(x, y)>F^{U}, \\ \frac{F^{L}-F(x, y)}{F^{U}-F^{L}} & \text { if } F^{L}<F(x, y)<F^{U}, \\ 0 & \text { if } F(x, y)<F^{L} .\end{cases}
$$

Let $t^{l}$ and $t^{R}$ be the maximum negative and positive tolerance values on the decision vectors considered by the upper level DM. The tolerances $t^{l}$ and $t^{R}$ are not necessarily the same:

$$
\begin{gathered}
\mu_{x}(x)= \begin{cases}\frac{x-\left(x^{U}-t^{L}\right)}{t^{L}} & \text { if } x^{U}-t^{L}<x<x^{U}, \\
0 & \text { if } x^{U}<x<x^{U}+t^{R},\end{cases} \\
\mu_{f_{i}}\left[f_{i}(x, y)\right]= \begin{cases}\frac{1}{\left.t^{R}+t^{R}\right)-x} & \text { if otherwise, } \\
f_{i}^{L}-f_{i}^{U} & \text { if } f_{i}^{U}(x, y)>f_{i}^{L}, \\
0 & \text { if } f_{i}(x, y)<f_{i}^{U} .\end{cases}
\end{gathered}
$$

2.2.2. Fuzzy Goal Programming Approach. In fuzzy programming approaches, the highest degree of membership function is one. According to [38], for the defined membership functions in (6) and (7), the flexible membership goals with the upper level can be presented as

$$
\begin{gathered}
\mu_{F}[F(x, y)]+d_{F}^{-}-d_{F}^{+}=1, \\
\mu_{x}(x)+d_{F}^{-}-d_{F}^{+}=1
\end{gathered}
$$

or equivalently as

$$
\begin{gathered}
\frac{F(x, y)-F^{L}}{F^{U}-F^{L}}+d_{F}^{-}-d_{F}^{+}=1, \\
\frac{x-\left(x^{U}-t^{L}\right)}{t^{L}}+d_{F}^{L-}-d_{F}^{L+}=1, \\
\frac{\left(x^{U}+t^{R}\right)-x}{t^{R}}+d_{F}^{R-}-d_{F}^{R+}=1,
\end{gathered}
$$

where $d_{F}^{-}=\left(d_{F}^{L-}, d_{F}^{R-}\right), d_{F}^{+}=\left(d_{F}^{L+}, d_{F}^{R+}\right)$, and $d_{F}^{-}, d_{F}^{L-}, d_{F}^{R-}$, $d_{F}^{+}, d_{F}^{L+}, d_{F}^{R+}$ with $d_{F}^{-} \times d_{F}^{+}=0, d_{F}^{L-} \times d_{F}^{L+}=0$ and $d_{F}^{R-} \times d_{F}^{R+}=0$, represent the under and over deviations, respectively, from the aspired levels.

Then, the proposed fuzzy bilevel multiobjective linear goal programming model of the problem can be presented under the framework of min-sum goal programming as follows:

upper level DM FGP model:

$$
\max Z=\omega_{F}^{+} d_{F}^{+}
$$


subject to

$$
\begin{gathered}
\frac{F(x, y)-F^{L}}{F^{U}-F^{L}}+d_{F}^{-}-d_{F}^{+}=1, \\
G(x, y) \leq 0, \quad g_{i}(x, y) \leq 0, \\
d_{F}^{-}, d_{F}^{+} \geq 0, \quad d_{F}^{-} \times d_{F}^{+}=0,
\end{gathered}
$$

lower level DM FGP model:

$$
\begin{aligned}
\max Z= & \omega_{F}^{+} d_{F}^{+}+\sum_{i=1}^{n} \omega_{2 i}^{+} d_{2 i}^{+}+\omega_{F}^{L}\left(d_{F}^{L-}+d_{F}^{L+}\right) \\
& +\omega_{1}^{R}\left(d_{F}^{R-}+d_{F}^{R+}\right)
\end{aligned}
$$

subject to

$$
\begin{gathered}
\frac{F(x, y)-F^{L}}{F^{U}-F^{L}}+d_{F}^{-}-d_{F}^{+}=1, \\
\frac{x-\left(x^{U}-t^{L}\right)}{t^{L}}+d_{F}^{L-}-d_{F}^{L+}=1, \\
\frac{\left(x^{U}+t^{R}\right)-x}{t^{R}}+d_{F}^{R-}-d_{F}^{R+}=1, \\
G(x, y) \leq 0, \quad g_{i}(x, y) \leq 0, \\
d_{F}^{-}, d_{F}^{+} \geq 0, \quad d_{F}^{-} \times d_{F}^{+}=0, \\
d_{F}^{L-}, d_{F}^{L+} \geq 0, \quad d_{F}^{L-} \times d_{F}^{L+}=0, \\
d_{F}^{R-}, d_{F}^{R+} \geq 0, \quad d_{F}^{R-} \times d_{F}^{R+}=0,
\end{gathered}
$$

where $Z$ represents the fuzzy achievement function consisting of the weighted over-deviational variables $d_{F}^{+}$of the fuzzy goals $F^{L}$, and the under-deviational and the over-deviational variables $d_{F}^{R-}, d_{F}^{R+}, d_{F}^{L-}$ and $d_{F}^{L+}$ for the fuzzy goals of all the decision variables for the upper level. The numerical weights $\omega_{F}^{+}, \omega_{2 i}^{+}, \omega_{F}^{L}$, and $\omega_{1}^{R}$ represent the relative importance of the respective fuzzy goals subject to the constraints set in the decision situation.

To assess the relative importance of the fuzzy goals properly, the weighting scheme suggested by Mohamed-decision makers can rank the $K$ objectives according to their priority [38] — can be used to assign the values to $\omega_{F}^{+}, \omega_{2 i}^{+}, \omega_{F}^{L}$ and $\omega_{1}^{R}$. In the present formulation, these values are determined as

$$
\begin{gathered}
\omega_{F}^{+}=\frac{1}{\left(F^{U}-F^{L}\right)}, \quad \omega_{2 i}^{+}=\frac{1}{\left(f_{i}^{L}-f_{i}^{U}\right)}, \\
\omega_{F}^{L}=\frac{1}{t^{L}}, \quad \omega_{1}^{R}=\frac{1}{t^{R}} .
\end{gathered}
$$

Using the fuzzy goal programming approach referred above, the calculating procedure is expressed as in the following steps.

Step 1. Calculate the individual values (minimum $F^{L}[=$ $\left.F\left(x^{L}, y^{L}\right)\right]$ and maximum $\left.f^{U}\left[=f\left(x^{U}, y^{U}\right)\right]\right)$ of all objective functions for the upper level and lower level under the given constraints.
Step 2. Set the goals and tolerances limits and evaluate the weights $\omega_{F}^{+}$for the objective function of the upper level.

Step 3. Elicit the membership function $\mu_{F}[F(x, y)]$ and formulate the transformed upper level model (15), (16), (17), (18), (19), (20), (21), and (22).

Step 4. Solve the transformed upper level model.

Step 5. Set the tolerance for $d_{F}^{-}, d_{F}^{L-}, d_{F}^{R-}, d_{F}^{+}, d_{F}^{L+}$, and $d_{F}^{R+}$ and evaluate the weights $\omega_{F}^{L}, \omega_{1}^{R}$.

Step 6. Elicit the membership function $\mu_{f_{i}}\left[f_{i}(x, y)\right]$ and formulate the transformed lower level model (23), (24).

Step 7. Solve the transformed lower level model to get the satisfactory solution of the BLMOP problem.

\section{Case Study}

3.1. Overview of the Study Area. The Wuwei Basin, Gansu Province, China (Figure 1), which is located in the eastern part of the Hexi Corridor (near Lanzhou, Qinghai, and Inner Mongolia), is an oasis-desert ecotone that links the Loess Plateau, Tibetan Plateau, and Mongolia-Xinjiang Plateau. [39, 40]. Wuwei is a typical continental climate region, with its average temperature of $7.80^{\circ} \mathrm{C}$ per year, average sunshine of 2968.2 hours per year, and frost-free period of 158 days per year. The rainfall is $161 \mathrm{~mm}$, and its evaporation is $2020 \mathrm{~mm}$ per year. The distribution of rainfall is uneven which accounted for $59.4 \%$ of the annual precipitation from July to September.

Due to the particular geography and the influence of human activities in Shiyang River Basin, the vegetation coverage of water conservation forest is decreasing, and the shortage of surface water resources is coming. The contradiction between supply and demand of water resources is increasing. Conflicts arise in the allocation of limited water resources among multiple competing interests, because each region prefers to maximize its own net benefit. But for the upper level decision makers, to balance the benefits of each region (lower level decision makers) is more important. Thus, bilevel programming is considered for the research area.

According to statistics annual reports published by Wuwei Water Affairs Bureau, the values per 1000 cube meters of water of each area are calculated (Table 2), which will be used as the coefficient of the upper level programming; the water price is selected as the coefficient of the lower level programming. Therefore, the upper level goal is the total benefit of Wuwei, and the lower level goal was the profit of water resources of each area.

According to Gansu Water Resources Bulletin (2009), the total amount of water supplied in 2009 is 1.91436 billion $\mathrm{m}^{3}$. Considering five-year (2005-2009) water resources datum, water demand numbers were calculated by trend forecasting method. The maximum and minimum water demands of each area are in Table 1. 


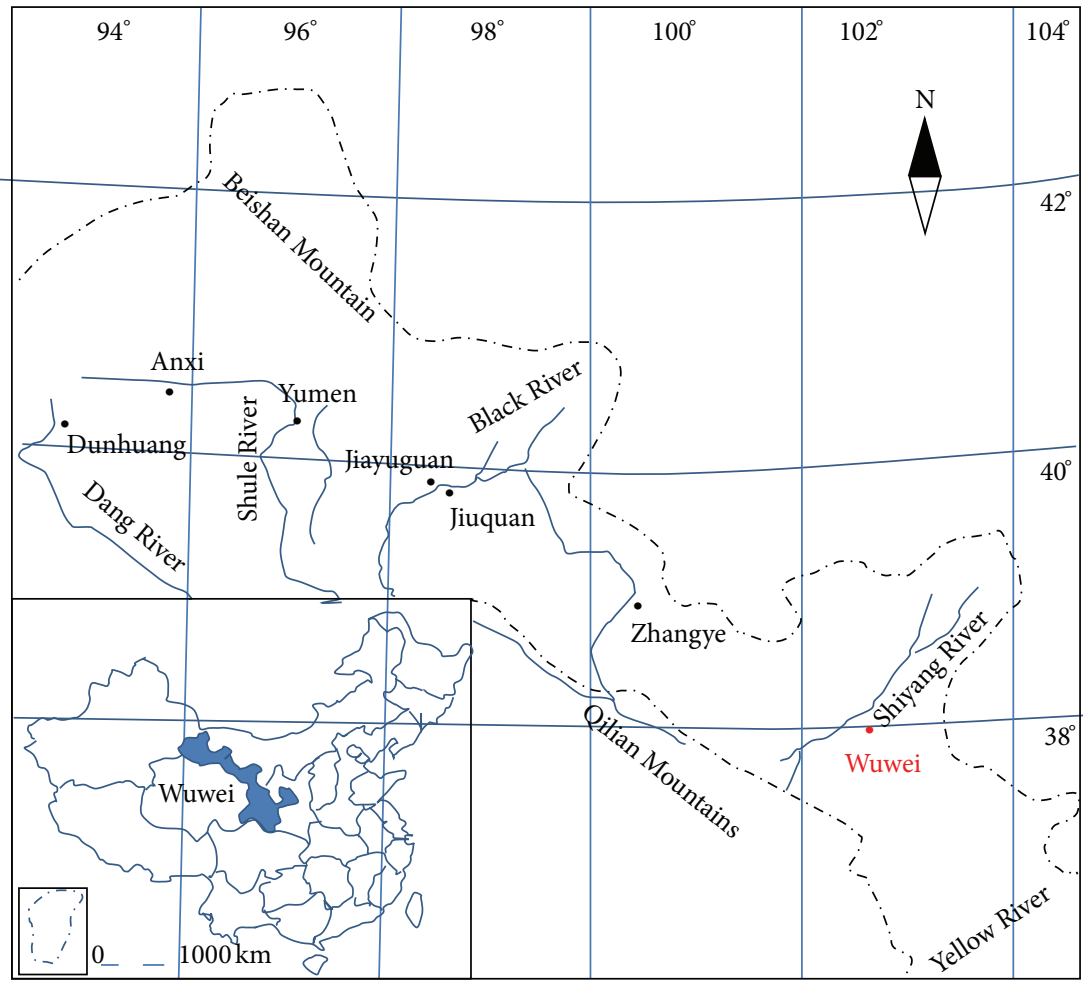

Figure 1: Location of the study area in Gansu Province.

TABLE 1: Water demand of each area.

\begin{tabular}{lccccc}
\hline Demand $10^{6}$ & Area & Irrigation & Industry & Domesticity & Ecology \\
\hline \multirow{3}{*}{ Maximum } & Liangzhou & 983.913 & 89.880 & 63.034 & 18.693 \\
& Minqin & 573.518 & 3.804 & 11.453 & 43.575 \\
& Gulang & 164.666 & 3.144 & 11.962 & 16.032 \\
& Tianzhu & 101.183 & 8.412 & 42.604 & 68.957 \\
Minimum & Liangzhou & 648.912 & 60.257 & 12.546 & 7.634 \\
& Minqin & 379.506 & 2.555 & 2.110 & 7.999 \\
\hline
\end{tabular}

TABLE 2: Coefficients of the upper-level and lower-level programming.

\begin{tabular}{|c|c|c|c|c|c|}
\hline \multirow{2}{*}{ Area } & \multirow{2}{*}{$\begin{array}{l}\text { ULP coefficient Yuan } /\left(1000 \mathrm{~m}^{3}\right) \\
\qquad C_{i}\end{array}$} & \multicolumn{4}{|c|}{ LLP coefficient $\left(\right.$ Yuan $\left./ \mathrm{m}^{3}\right)$} \\
\hline & & Irrigation & Industry & Domesticity & Ecology \\
\hline Liangzhou & 139.28 & 0.11 & 1.9 & 1.85 & 0.11 \\
\hline Minqin & 54.66 & 0.208 & 3.5 & 1.8 & 0.15 \\
\hline Gulang & 132.45 & 0.13 & 2.8 & 1.8 & 0.13 \\
\hline Tianzhu & 163.28 & 0.1 & 0.15 & 1.1 & 0.13 \\
\hline
\end{tabular}

3.2. Modeling Formulation and Calculating Procedure. The problem under consideration is how to allocate water resources. The upper level decision makers wanted to get the maximum benefits of the whole system, while the lower level decision makers would like to maximize their own profits. Then the objects of the problem are shown as follows: (upper level)

$$
\max F=\sum_{i=1}^{4}\left(C_{i} \cdot \sum_{j=1}^{4} x_{i j}\right),
$$




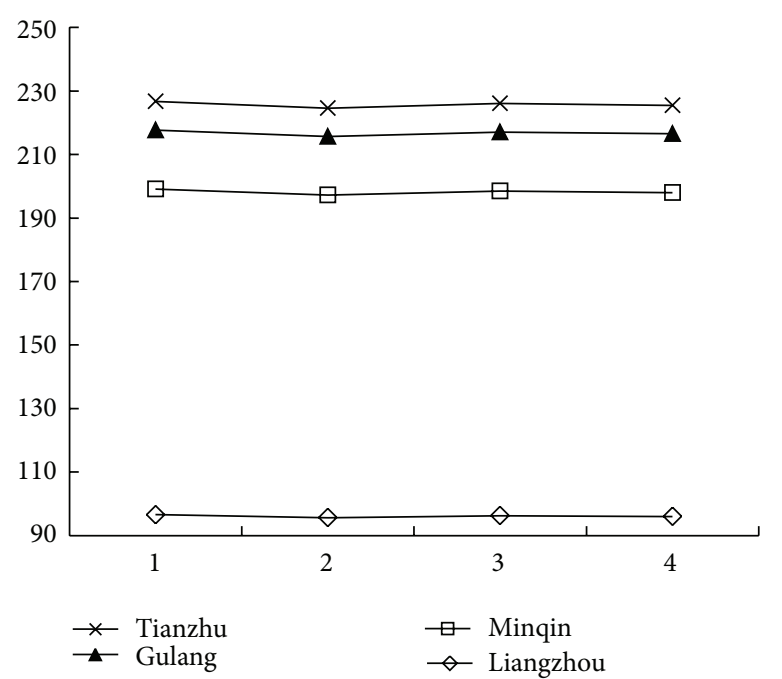

(a)

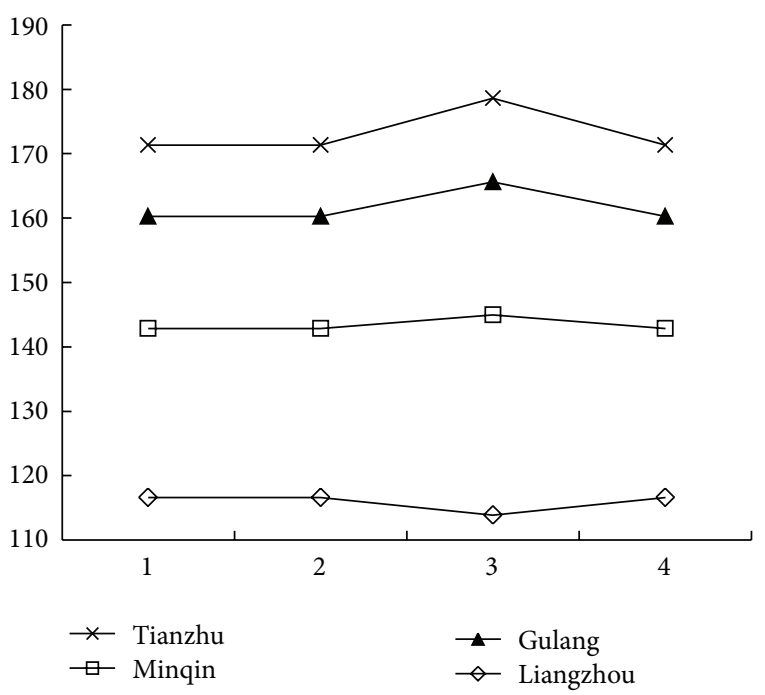

(c)

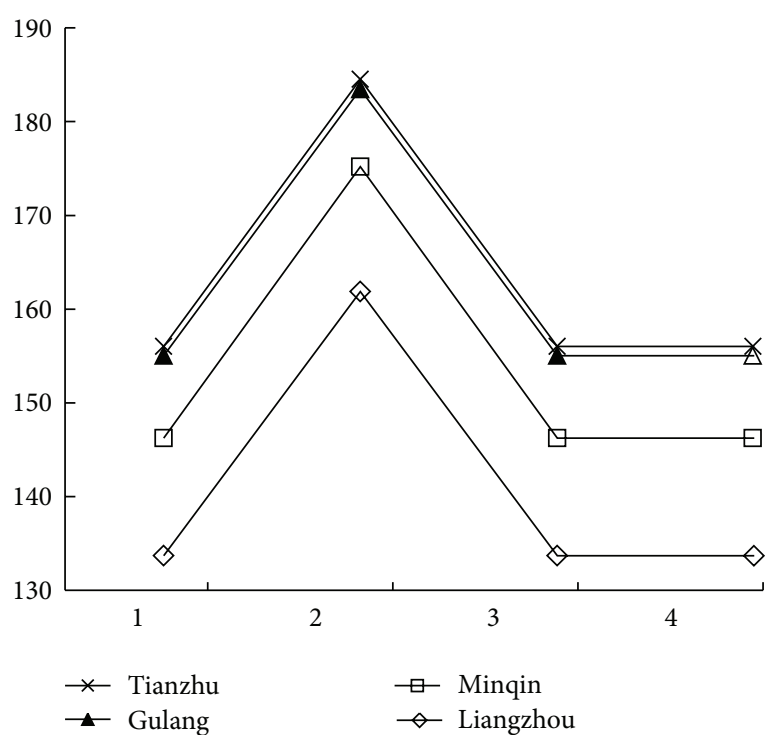

(b)

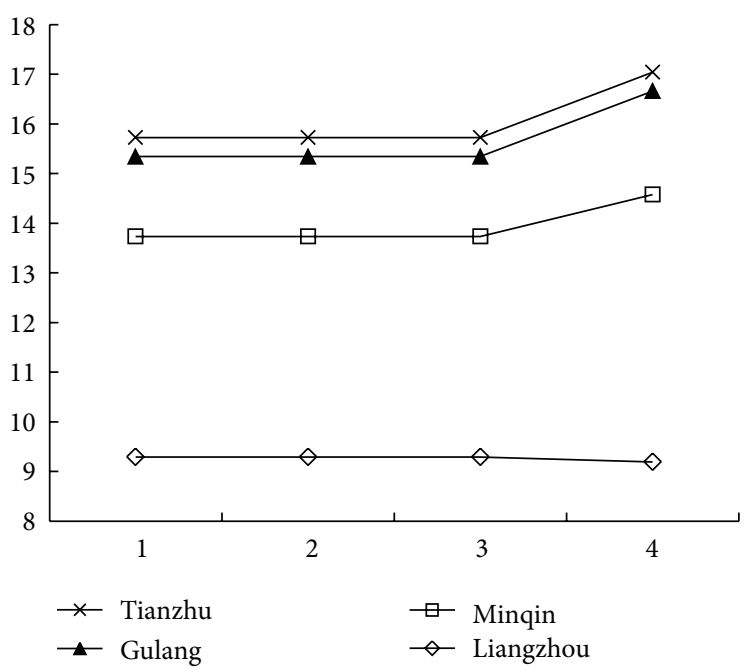

(d)

Figure 2: Different benefits ( $10^{9}$ Yuan) accumulated diagrams under different scenarios. (a) Irrigation benefits accumulated diagram under different scenarios. (b) Industry benefits accumulated diagram under different scenarios. (c) Domesticity benefits accumulated diagram under different scenarios. (d) Ecology benefits accumulated diagram under different scenarios.

(lower level)

$$
\max f_{i}=\sum_{j=1}^{4} d_{i j} \cdot x_{i j}
$$

subject to

(1) total amount not more than available water supply

$$
\sum_{i=1}^{4} \sum_{j=1}^{4} x_{i j} \leq T
$$

(2) not less than minimum water supply

$$
x_{i j} \geq x_{\min i j},
$$

(3) not more than maximum water supply

$$
x_{i j} \leq x_{\max i j}
$$

(4) regional coordination development

$$
\mu \geq \mu^{*},
$$

(5) nonnegative constraints

$$
x_{i j} \geq 0 \text {, }
$$


TABLE 3: Results of the regional water resources allocation.

\begin{tabular}{|c|c|c|c|c|c|}
\hline \multirow{2}{*}{ Areas } & \multicolumn{5}{|c|}{ Allocated water $\left(10^{6} \mathrm{~m}^{3}\right)$} \\
\hline & Irrigation & Industry & Domesticity & Ecology & Total \\
\hline \multicolumn{6}{|c|}{ Scenario 1 irrigation priority } \\
\hline Liangzhou & 877.709 & 70.360 & 63.034 & 84.486 & 1095.589 \\
\hline Minqin & 492.959 & 3.584 & 14.565 & 29.584 & 540.692 \\
\hline Gulang & 143.280 & 3.144 & 9.685 & 12.384 & 168.493 \\
\hline Tianzhu & 89.940 & 6.654 & 10.035 & 2.957 & 109.586 \\
\hline \multicolumn{6}{|c|}{ Scenario 2 industry priority } \\
\hline Liangzhou & 868.851 & 85.200 & 63.034 & 84.486 & 1101.572 \\
\hline Minqin & 488.531 & 3.804 & 14.565 & 29.584 & 536.484 \\
\hline Gulang & 141.951 & 2.943 & 9.685 & 12.384 & 166.963 \\
\hline Tianzhu & 89.054 & 7.295 & 10.035 & 2.957 & 109.342 \\
\hline \multicolumn{6}{|c|}{ Scenario 3 domesticity priority } \\
\hline Liangzhou & 874.984 & 70.360 & 61.543 & 84.486 & 1091.373 \\
\hline Minqin & 491.597 & 3.584 & 17.291 & 29.584 & 542.055 \\
\hline Gulang & 142.871 & 3.144 & 11.453 & 12.384 & 169.851 \\
\hline Tianzhu & 89.667 & 6.654 & 11.803 & 2.957 & 111.081 \\
\hline \multicolumn{6}{|c|}{ Scenario 4 ecology priority } \\
\hline Liangzhou & 872.559 & 70.360 & 63.034 & 83.576 & 1089.529 \\
\hline Minqin & 490.384 & 3.584 & 14.565 & 35.903 & 544.437 \\
\hline Gulang & 142.507 & 3.144 & 9.685 & 16.032 & 171.369 \\
\hline Tianzhu & 89.425 & 6.654 & 10.035 & 2.911 & 109.026 \\
\hline
\end{tabular}

where

$x_{i j}$ are decision variables, water allocated to each users, $10^{6}$ are cube meters $\left(10^{6} \mathrm{~m}^{3}\right)$,

$F$ are benefits of upper level programming, Yuan,

$f_{i}$ are profits of lower level programming, Yuan,

$C_{i}$ are values per 1000 cube meters, Yuan per 1000 cube meters,

$d_{i j}$ is water price per cube meter, Yuan $/ \mathrm{m}^{3}$,

$T$ is total amount of available water supplement,

$x_{\min i j}$ is minimum water demand of each area, $10^{6} \mathrm{~m}^{3}$,

$x_{\max i j}$ is maximum water demand of each area, $10^{6} \mathrm{~m}^{3}$,

$\mu$ is regional coordination value, dimensionless.

According to the procedure above, four scenarios are set, and the satisfactory solutions are shown in Table 3. In scenario 1 , the decision makers emphasise on irrigation benefits, and in scenario 2 to scenario 4, DMs emphasise on the industry benefits, domesticity benefits, and ecology benefits, respectively.

\section{Results Analysis}

The detailed satisfactory solutions in Table 3 are parts of the optimal solutions of the BLMOLP model for water resources allocation. Because the different tolerance limit had a corresponding solution for the model, multioptimal solutions will emerge. However, the deviation of each result is tiny. The progress of the solution suggests that fuzzy goal programming is a user friendly method. For a specific target, there is a little alteration in the objective goal.

Irrigation water allocated is about $84 \%$ of the total amount of water on average and is nearly the same as the figure of the former 5 years. In scenario 1, irrigation water allocated is about $5 \times 10^{6} \mathrm{~m}^{3}$ more than the other three scenarios on average. While DMs give priorities to the industry users (scenario 2), the water allocated for industry is over $16 \times 10^{6} \mathrm{~m}^{3}$ more than the other three scenarios on average. The probable reason for this is that the coefficient of industry water use is higher than the coefficient of irrigation water use. In other words, even if the DMs prefer the irrigation users, the water allocated to the department would not increase too much. In this regard, in the Minqin area, the coefficient of ecology is higher than the other areas, so in scenario 4 the water allocated increases a lot. However, in scenario 4, the other areas' water allocation decreases a bit. It is because the model needs to balance the net water allocation. We also notice that in scenario 2 Liangzhou gets the highest water allocation, and the result is coherent to actual circumstances. Liangzhou is the main area of industry output, so a slight change would influence the result, especially, when DMs emphasise on industry. Figure 2 shows the benefit variousness under different scenarios for different users. For irrigation users, the benefits keep a constant level in the limited increase due to 
the upper level objects' constrains. And the variousness of the industry users' benefits reflects the adaptability of the lowerlevel decision makers to the upper level decision changes. According to Figure 2, although the upper level decision makers emphasise on domesticity and ecology water users, there are a slight decrease in Liangzhou. This also inflects the upper level constrains to the lower level objects, because the total benefits reflect an upward trend. However, the results also indicate the subjectivity of the bilevel programming. When the upper level decision maker cannot choose the specific benefits he/she cared for, the result of the programming is confusing for the lower level decision makers. Another disadvantage of fuzzy goal programming is that the determination of numerical weights is difficult. Based on the fuzzy membership functions, there is not too much complicated calculation. Anyway, fuzzy goal programming is flexible for bilevel programming.

\section{Conclusions}

A bilevel multiobjective linear programming (BLMOLP) model is discussed in this paper and applied to Wuwei Basin in Shiyang River, Gansu Province, China. Water resources allocation involved several decision makers including the leaders and the subordinates. Using the fuzzy goal programming to solve the problem, by setting the tolerance value, the result could be calculated easily. Fuzzy goal programming approach is developed to minimize the group regret of degree of satisfactions of all DMs. In this research, the deviational variables of the defined membership functions are minimized to achieve the highest degree. The result of the BLMOLP model can be used for the water allocation in the Wuwei area; meanwhile, the model also can be generalized to a broader area. However, the formulation is a typical linear programming in this research. In practical situations, the water resources system may be nonlinear, and the relationship between the water users or the decision makers is more complicated. Therefore, nonlinear programming will be studied in the future, and the fuzzy goal approach also can be used. As well, a bilevel multiobjective nonlinear programming (BLMONLP) model can be studied for the water resources system, even for the energy system, waste disposal problem.

\section{Acknowledgments}

This research was supported by the National Natural Science Foundation of China (nos. 71071154 and 91125017), National High Technology Research and Development Program of China (863 Program) (no. 2011AA100502), the Government Public Research Funds for Projects of Ministry of Agriculture (no. 201203077), and the Ministry of Water Resources (nos. 201001060 and 201001061).

\section{References}

[1] D. Prinz and A. K. Singh, "Water resources in arid regions and their sustainable management," Annals of Arid Zone, vol. 39, no. 3, pp. 251-271, 2000.
[2] D. P. Loucks, E. van Beek, J. R. Stedinger et al., Water Resources Systems Planning and Management: An Introduction to Methods, Models and Applications, UNESCO, Paris, France, 2005.

[3] A. K. Biswas, "Integrated water resources management: a reassessment," Water International, vol. 29, no. 2, pp. 248-256, 2004.

[4] W. O. Maddaus and J. M. McGill, "Development and application of a water resource allocation model.," Water Resources Research, vol. 12, no. 4, pp. 767-774, 1976.

[5] R. P. Lejano and C. A. Davos, "Cost allocation of multiagency water resource projects: game theoretic approaches and case study," Water Resources Research, vol. 31, no. 5, pp. 1387-1393, 1995.

[6] E. F. Y. Gakpo, L. A. D. Plessis, and M. F. Viljoen, “Towards institutional arrangements to ensure optimal allocation and security of South Africa's water resources," Agrekon, vol. 40, no. 1, pp. 87103, 2001.

[7] H. Lévite, H. Sally, and J. Cour, "Testing water demand management scenarios in a water-stressed basin in South Africa: application of the WEAP model," Physics and Chemistry of the Earth, vol. 28, no. 20-27, pp. 779-786, 2003.

[8] I. Fischhendler, "Institutional conditions for IWRM: the Israeli case," Ground Water, vol. 46, no. 1, pp. 91-102, 2008.

[9] G. N. Paudyal and H. B. Manguerra, "Two-step dynamic programming approach for optimal irrigation water allocation," Water Resources Management, vol. 4, no. 3, pp. 187-204, 1990.

[10] R. Wardlaw and K. Bhaktikul, "Application of a genetic algorithm for water allocation in an irrigation system," Irrigation and Drainage, vol. 50, no. 2, pp. 159-170, 2001.

[11] L. Z. Wang, L. Fang, and K. W. Hipel, "Water resources allocation: a cooperative game theoretic approach," Journal of Environmental Informatics, vol. 2, no. 2, pp. 11-22, 2003.

[12] F. Messner, O. Zwirner, and M. Karkuschke, "Participation in multi-criteria decision support for the resolution of a water allocation problem in the Spree River basin," Land Use Policy, vol. 23, no. 1, pp. 63-75, 2006.

[13] Y. P. Li, G. H. Huang, Y. F. Huang, and H. D. Zhou, "A multistage fuzzy-stochastic programming model for supporting sustainable water-resources allocation and management," Environmental Modelling and Software, vol. 24, no. 7, pp. 786-797, 2009.

[14] M. Sadegh, N. Mahjouri, and R. Kerachian, "Optimal interbasin water allocation using crisp and fuzzy Shapley games," Water Resources Management, vol. 24, no. 10, pp. 2291-2310, 2010.

[15] M. Sadegh and R. Kerachian, "Water resources allocation using solution concepts of fuzzy cooperative games: fuzzy least core and fuzzy weak least core," Water Resources Management, vol. 25, no. 10, pp. 2543-2573, 2011.

[16] L. G. Shao, X. S. Qin, and Y. Xu, "A conditional value-at-risk based inexact water allocation model," Water Resources Management, vol. 25, no. 9, pp. 2125-2145, 2011.

[17] L. Jin, G. H. Huang, Y. R. Fan et al., "A hybrid dynamic dual interval programming for irrigation water allocation under uncertainty," Water Resources Management, vol. 26, no. 5, pp. 1183-1200, 2012.

[18] E. Xevi and S. Khan, "A multi-objective optimisation approach to water management," Journal of Environmental Management, vol. 77, no. 4, pp. 269-277, 2005. 
[19] A. P. Singh, S. K. Ghosh, and P. Sharma, "Water quality management of a stretch of river Yamuna: an interactive fuzzy multiobjective approach," Water Resources Management, vol. 21, no. 2, pp. 515-532, 2007.

[20] A. A. Fasakhodi, S. H. Nouri, and M. Amini, "Water resources sustainability and optimal cropping pattern in farming systems; a multi-objective fractional goal programming approach," Water Resources Management, vol. 24, no. 15, pp. 4639-4657, 2010.

[21] W. Candler and R. D. Norton, "Multi-level programming," World Bank, 1977.

[22] H. S. Shih, Y. J. Lai, and E. S. Lee, "Fuzzy approach for multi-level programming problems," Computers \& Operations Research, vol. 23, no. 1, pp. 73-91, 1996.

[23] K. B. Aviso, R. R. Tan, A. B. Culaba, and J. B. Cruz, "Bi-level fuzzy optimization approach for water exchange in eco-industrial parks," Process Safety and Environmental Protection, vol. 88, no. 1, pp. 31-40, 2010.

[24] A. N. Sadigh, M. Mozafari, and B. Karimi, "Manufacturerretailer supply chain coordination: a bi-level programming approach," Advances in Engineering Software, vol. 45, no. 1, pp. 144-152, 2012.

[25] J. Wonga, C. Su, and C. Wang, "Stochastic dynamic lot-sizing problem using bi-level programming base on artificial intelligence techniques," Applied Mathematical Modelling, vol. 36, no. 5, pp. 2003-2016, 2012.

[26] Y. Lv, G. H. Huang, Y. P. Li, Z. F. Yang, Y. Liu, and G. H. Cheng, "Planning regional water resources system using an interval fuzzy bi-level programming method," Journal of Environmental Informatics, vol. 16, no. 2, pp. 43-56, 2010.

[27] B. Colson, P. Marcotte, and G. Savard, "Bilevel programming: a survey," 4OR, vol. 3, no. 2, pp. 87-107, 2005.

[28] W. Candler and R. Townsley, "A linear two-level programming problem," Computers \& Operations Research, vol. 9, no. 1, pp. 59-76, 1982.

[29] C. Shi, J. Lu, and G. Zhang, "An extended Kth-best approach for linear bilevel programming," Applied Mathematics and Computation, vol. 164, no. 3, pp. 843-855, 2005.

[30] W. F. Bialas and M. H. Karwan, "Two-level linear programming," Management Science, vol. 30, no. 8, pp. 1004-1020, 1984.

[31] J. F. Bard and J. T. Moore, "A branch and bound algorithm for the bilevel programming problem," Siam Journal on Scientific and Statistical Computing, vol. 11, no. 2, pp. 281-292, 1990.

[32] A. Charnes and W. W. Cooper, "Management models and industrial applications of linear programming," Management Science, vol. 4, no. 1, pp. 38-91, 1957.

[33] B. Moitra and B. Pal, "A fuzzy goal programming approach for solving bilevel programming problems," Advances in Soft Computing-Afss, vol. 2275, pp. 415-421, 2002.

[34] B. B. Pal and B. N. Moitra, "A fuzzy goal programming procedure for solving quadratic bilevel programming problems," International Journal of Intelligent Systems, vol. 18, no. 5, pp. 529540, 2003.

[35] S. Pramanik and T. K. Roy, "Fuzzy goal programming approach to multilevel programming problems," European Journal of Operational Research, vol. 176, no. 2, pp. 1151-1166, 2007.

[36] S. R. Arora and R. Gupta, "Interactive fuzzy goal programming approach for bilevel programming problem," European Journal of Operational Research, vol. 194, no. 2, pp. 368-376, 2009.

[37] I. A. Baky, "Solving multi-level multi-objective linear programming problems through fuzzy goal programming approach,"
Applied Mathematical Modelling, vol. 34, no. 9, pp. 2377-2387, 2010.

[38] R. H. Mohamed, "The relationship between goal programming and fuzzy programming," Fuzzy Sets and Systems, vol. 89, no. 2, pp. 215-222, 1997.

[39] F. You, Y. Li, and S. C. Dong, "Environmental sustainability and scenarios of urbanization in arid area: a case study in Wuwei City of Gansu Province," Chinese Geographical Science, vol. 15, no. 2, pp. 120-130, 2005.

[40] J. Ma, Z. Ding, G. Wei, H. Zhao, and T. Huang, "Sources of water pollution and evolution of water quality in the Wuwei basin of Shiyang river, Northwest China," Journal of Environmental Management, vol. 90, no. 2, pp. 1168-1177, 2009. 


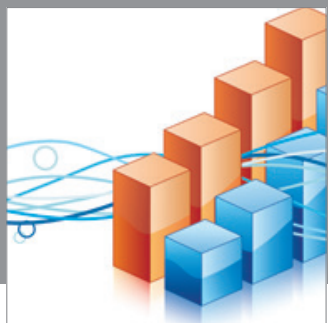

Advances in

Operations Research

mansans

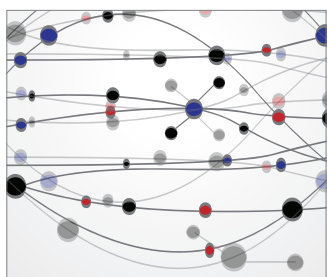

The Scientific World Journal
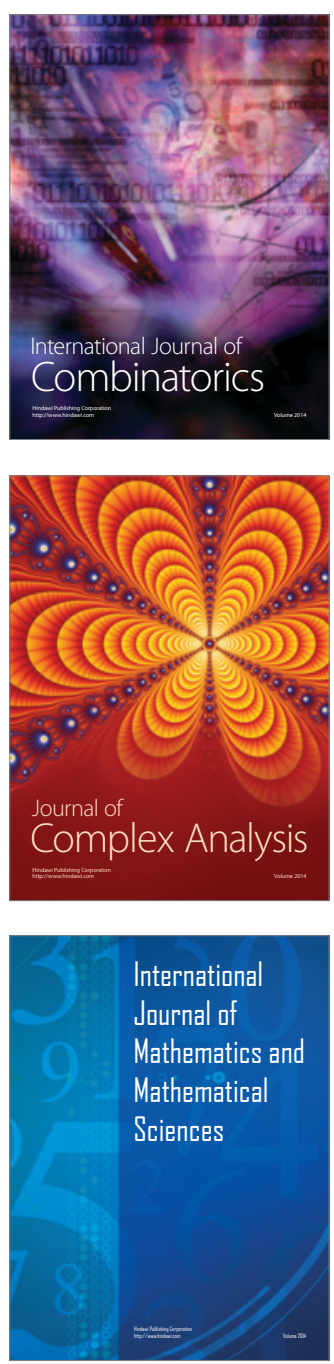
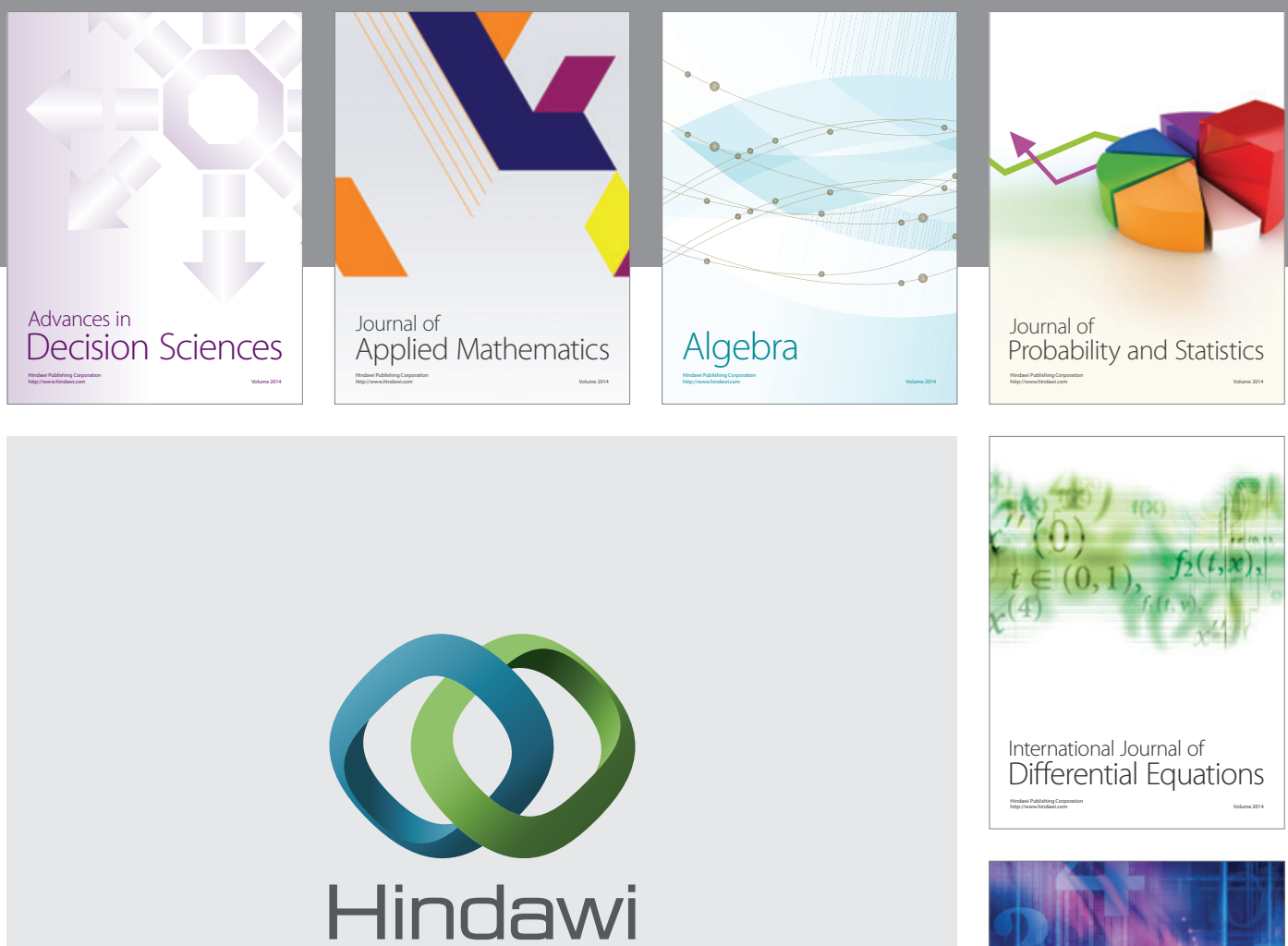

Submit your manuscripts at http://www.hindawi.com
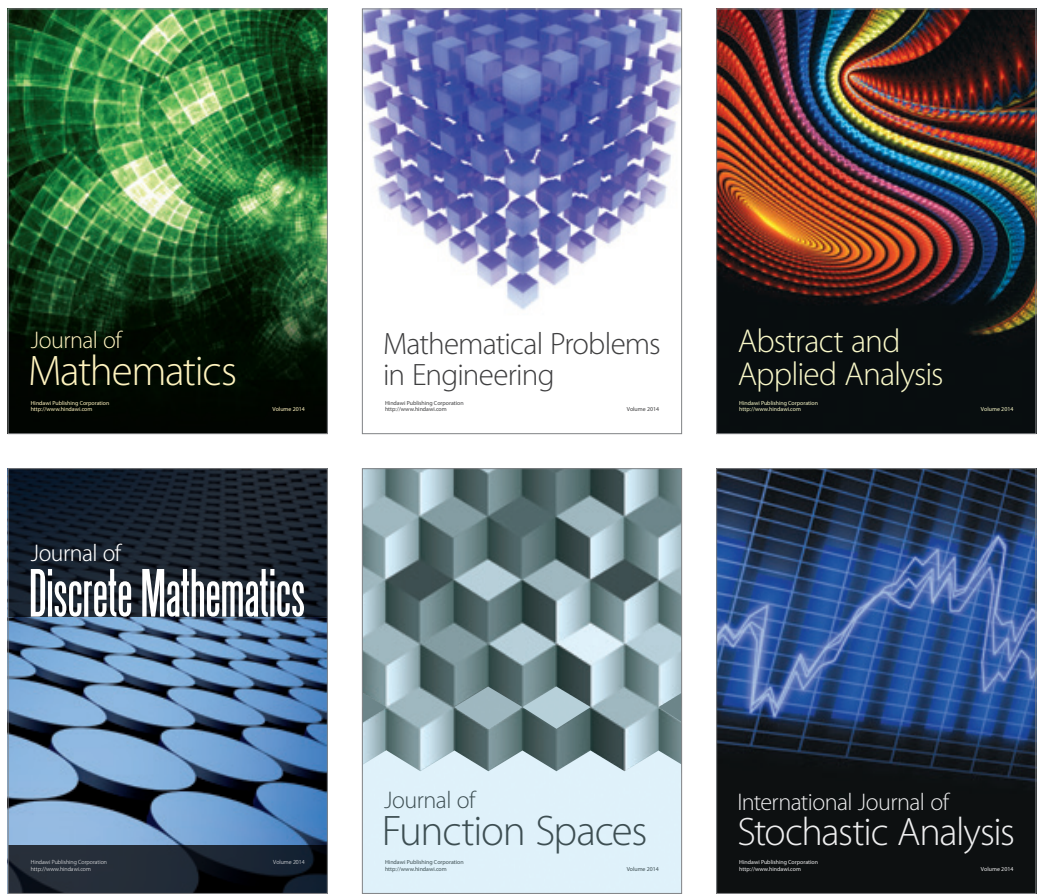

Journal of

Function Spaces

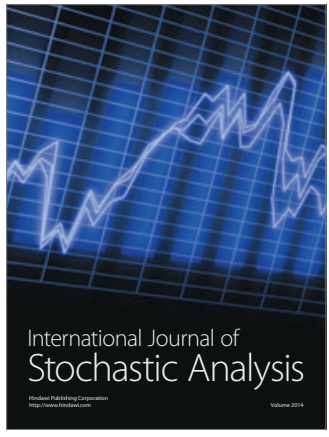

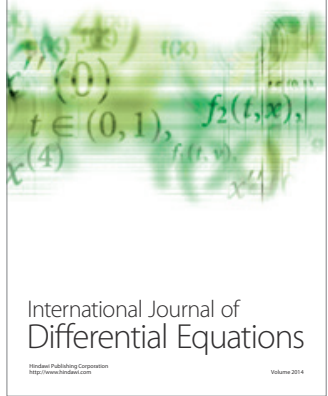
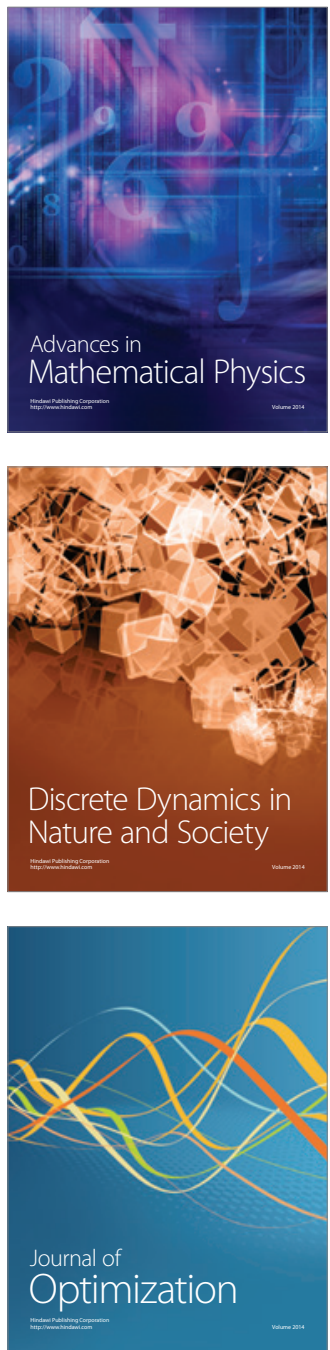